The Oxford Book of Birds

By B. Campbell and D. Watson. Pp. xvi+ 207 (illustrations). (London: Oxford University Press, 1964.) $35 s$.

$\triangle$ MONG the many current books on British birds, $A$ this may be acclaimed the best at its particular level, between the pocket guide to identification and the advanced text-book. It is indeed excellent for identifica. tion purposes, but it also gives a satisfying amount of solid information on distribution, habitat and behaviour. Each of the 96 colour plates depicts several species, and two or more examples where there are important differences in plumage according to sex, age or season. All species that have occurred in the British Isles are figured except a few rare vagrants, and even some of these and of introduced species that have become locally naturalized. Mr. Watson is skilful with his brush and obviously knows most of his subjects in life. These are shown in a 'natural' setting; although this raises occasional difficulties of scale and involves some incongruities of juxtaposition, it has the advantage of immediately relating the bird to its habitat and at the same time produces a pleasing picture. The standard of colour reproduction is high, although in certain instances some predominant tint appears to be too strong.

The text is thoroughly reliable and up to date. It is conveniently arranged with from one to three paragraphs about each species on the page facing its illustration. Dr. Campbell has succeeded in compressing a great deal of information into limited space, by careful selection and by using an economical style; the result is pleasantly readable. He has also avoided overloading the text with information that is irrelevant to the British status of the species, such as the breeding habits of those that are not natives. For the commoner birds tho treatment ends with an ingenious single-line calendar-a series of numbers, with typographic variations, that shows at a glanee in which months the species is $(a)$ present, $(b)$ nesting, and $(c)$ in song.

At the beginning and end of the book there are useful brief chapters on general subjects such as classification, anatomy, flight, behaviour and breeding, migration and numbers. Black-and-white drawings illustrate these and also show the appearance of various waders and ducks on the wing.

LandsBorougri Thomson

\section{Intersexuality in Vertebrates Including Man}

Edited by C. N. Armstrong and A. J. Marshall. Pp. $x i+479$. (London: Academic Press, Tnc. (London), Ltd.; Now York: Academic Press, Inc., 1964.) 90s. net.

THE scope of this excellent text-book is logical but unusual, in combining a series of review articles directed chiefly to zoologists, with two outstanding clinical reviews. In the context of biology it is eminently reasonable to discuss intersexuality in vertebrates by phyla, ending with a special discussion of it in man; it is none the less a relatively new gesture by publishers in the direction of an interdisciplinary human biology; this approach is so useful that one must hope that the clinical sections are not overlooked by medical readers, coming as they do after a sizable body of zoology.

Intersexual phenomena, normal and pathological, are a good deal commoner in vertebrates than had been realized until recently - the number of known examples of hermaphroditism in fish, for example, has been growing steadily since the beginning of the present century. The bulk of this book is taken up with a series of good specialist reviews - of fishes (J. W. Atz), amphibia (C. L. Foote), reptiles (T. R. Forbes), birds (E. Taber) and non-human mammals (J. Bruner-Lorand), prefaced by a full discussion of vertebrate chromosome deviations by R. A. Beatty, excluding those in man. There is also an informative and entertaining editorial foreword by A. J. Marshall. Human intersexuality is then dealt with in full clinical detail, together with the present state of knowledge about human chromosome anomalies, by C. N. Armstrong. This article is well illustrated with case photographs and histories, and preceded by a series of paragraphs on the legal and logical definitions of maleness or femaleness. Both as a summary of sex-determination in man, and as a short primer of an obscure but important clinical problem in differential diagnosis, this would be hard to better. Especially welcome, however, is the good judgment of the editors in following this essay with another, by M. Roth and J. B. Ball, on the behavioural types of intersexuality in man (homosexuality, trans-sexualism, transvestism) depending on the mis-learning of a gender role, which should serve once and for all to end the confusion between these states and that of physical intersexuality. An incidental but important use of the reviews of phyla is that they provide most valuable data for the seloction of experimental animals. Bibliographies are adequate without being inflated, illustrations are good, and the style of the whole is readable. The book is a most useful addition to the library of any department or worker concerned with cytology, zoology, veterinary surgery, or clinical medicine-or with the teaching of these at pre- and post-graduate levels. ALEx COMFORT

\section{The Natural Radiation Environment}

Edited by Prof. John A. S. Adams and Wayne M. Lowder. Pp. xiv +1069 . (Chicago and London: University of Chicago Press, 1964. Published for William Marsh Rice University.) $105 s$.

$T$ HE proceedings of seientific conforences or symposia are not usually the best material for a text-book, since there is no reasoned account of the fundamental parts of the subject and the papers tend to be heterogeneous in outlook. International symposia tend to suffer from a further disadvantage: presentation of a paper is frequently the passport to the meeting, with the result that many relatively poor papers are written. It is only the major workers in the field, and as a rule the contributors from abroad, who can bo relied on for really good papers, the latter primarily because the expense of sending them must be justified by a significant contribution to the conference. This is evident in The Natural Radiation Environment, where the average standard of the American papers is well below that of the European contributions. The main eriticism that can be levelled at some of the authors is that their topics are parochial in the extreme and make little contribution to the overall knowledge of the subject. The book as a whole-and presumably, therefore, the symposium-suffers from too wide a diversity of interest and it is occasionally difficult to see how a paper fits into the general scheme.

The subject-matter is divided into two main sections: the first, entitled "Environmental Radiation Sources", includes radioactivity in the earth, in water and in the atmosphere, $\alpha$-radioactivity (on which one of the best papers has been written) and cosmic radiation. The second part, "Environmental Radiation Measurements", includes instrumentation and techniques, aerial surveys and ground measurements and surveys. Apart from one or two notable excoptions, the second part probably contributes more to our knowledge of the subject than does the first.

A short section is devoted to an intercalibration experiment carried out on the day before the symposium. In this, six different instruments, five from the United States and one from Great Britain, were used in three environments of widely differing natural radiation-levels. The results are interesting, but more could be made of them.

This is certainly not a general text-book on environmental radiation. It has perhaps much for the specialist, but its diversity and its price will fail to attract a wide audience.
H. D. Evans 